\title{
Plasma Frio aplicado em mangas da variedades Coquinho
}

\author{
Alves, D. P. ${ }^{1^{*}}$; Pinheiro, C. J. G. ${ }^{2}$; Cristo, K. V. ${ }^{3}$; Passamai J. L. ${ }^{4}$; Carneiro J. C. S $^{5}$ \\ 1 Programa de Pós-Graduação em Engenharia Química, Universidade Federal do Espírito Santo, Alegre, ES, Brasil. \\ 2 Departamento de Engenharia Rural, Universidade Federal do Espírito Santo, Alegre, ES, Brasil. \\ 3 Graduação em Farmácia, Faculdade do Futuro, Manhuaçu, MG, Brasil. \\ 4 Departamento de Física, Universidade Federal do Espírito Santo, Vitória, ES, Brasil. \\ 5 Departamento de Engenharia de Alimentos, Universidade Federal do Espírito Santo, Alegre, ES, Brasil.
}

* e-mail: douglas.palves15@gmail.com

\begin{abstract}
Resumo
Atualmente existem várias técnicas para a conservação e esterilização de alimentos, entretanto, muitas destas técnicas não preservam as características originais do produto como, por exemplo, o caso da fermentação. Outros métodos como a esterilização por meio de radiação ionizante, embora eficaz, possuem alto custo desde a construção de instalações até o deslocamento dos produtos a serem irradiados. Tecnologias consideradas emergentes no tratamento não térmico, em especial o tratamento a plasma frio estão se mostrando eficaz no controle de bactérias deteriorantes ou patogênicas, com baixa perda sensorial e/ou nutricional. Neste trabalho objetivamos esterilizar mangas da variedade coquinho utilizando plasma frio à pressão atmosférica. Com uma aplicação de 3 minutos as mangas apresentaram um retardamento na maturação em relação ao controle.
\end{abstract}

Palavras chave: plasma frio, tratamento não térmico de alimentos, esterilização.

\begin{abstract}
Currently we have several techniques for the preservation and sterilization of food, However, many of these techniques do not preserve the original characteristics of the product, such as the case of fermentation. Other methods such as sterilization by means of ionizing radiation, although effective, have a high cost from the construction of facilities to the displacement of the products to be irradiated. Technologies considered to be emerging in non-thermal treatment, especially cold plasma treatment, are proving effective in controlling deteriorating or pathogenic bacteria, with low sensorial and / or nutritional loss. In this work we aim to sterilize mangoes of the coquinho variety using cold plasma at atmospheric pressure. With a 3 minute application, the mangoes showed a delay in maturation in relation to the control.
\end{abstract}

Keywords: Cold plasma, Non-thermal food treatment, Sterilization

\section{Introdução}

Segundo a Food and Agriculture Organization of the United Nations (FAO) no ano de 2015 eram mais de 800 milhões de pessoas no mundo passando fome, principalmente em países em desenvolvimento [1]. Já em 1996 o estoque de alimento era o suficiente para atender as necessidades diárias de toda a população $[1,2]$. Ou seja, a questão não é a produção de alimentos, mas deslocar o alimento até o consumidor sem perdas [2].

Só no Brasil, as perdas agrícolas chegam a equivaler a $7,8 \%$ do produto interno bruto brasileiro (PIB), algo em torno de $\mathrm{R} \$ 10$ bilhões [2]. Devido ao seu alto grau de perecibilidade, cerca de $30 \%$ a $40 \%$ das hortaliças e frutas produzidas no Brasil são perdidas [2]. Com isso 0 aprimoramento e uso de novas técnicas de conservação de alimento se faz muito necessário.

Alguns métodos de conservação como a fermentação e a secagem alteram o sabor, o aspecto e até mesmo os nutrientes do alimento [3].

Mesmo o uso de radiação ionizante que apresenta grandes vantagens no tratamento de alimentos destruindo microrganismos causadores de intoxicações, e aumentando o tempo de prateleira de produtos, apresenta desvantagens [4,5]. O seu uso bem como a construção de uma planta para irradiação e treinamento de pessoal contêm altos custos, sem contar os riscos de acidentes com materiais radioativos que podem eventualmente acontecer [5].

Recentemente grande atenção tem se dado aos processos de tratamento não térmicos, se destacam 
nesse processo segurança e a qualidade, sem comprometer as características sensoriais, funcionais e nutricionais dos alimentos [6].

Em relação à estas novas técnicas de processamento não térmico uma atenção especial tem se dado ao plasma frio à pressão atmosférica, sendo ele uma alternativa promissora aos métodos de pasteurização [6]. Devido ao seu caráter não térmico, alterações típicas do tratamento térmico como mudanças na coloração, formação de odores não característicos do alimento, sabores indesejáveis e perdas dos valores nutricionais podem ser minimizados, além de um aumento de vida útil $[6,7]$.

O termo "plasma" é usado em Física para descrever um gás eletricamente condutor, este gás é constituído por partículas livres carregadas e não carregadas, íons, elétrons, nêutrons, átomos e moléculas que exibem um comportamento coletivo graças às forças coulombianas $[8,9]$. O plasma foi identificado pela primeira vez em 1879 pelo físico inglês Wiliam Crookes como um novo estado da matéria, porém, foi somente em 1929 que o cientista americano Irving Langmuir utilizou o termo "plasma" ao tratar de um gás ionizado [9]. Devido às suas características, o plasma é considerado "O quarto estado da matéria", além dos demais sólido, liquido e gasoso $[8,9,10]$.

O uso de plasma para esterilização de superfícies e materiais já é regulamentado pelo ministério da saúde [11].

O poder de esterilização do plasma deve-se aos íons contidos no mesmo, as espécies reativas, tais como ozônio, moléculas de oxigênio metaestáveis e radicais hidroxil que são produzidas no contato do plasma com o ar, e a radiação ultravioleta (UV) cujo poder esterilizante já é bem conhecido [6,11]. Estas espécies reativas se reorganizam e interagem com moléculas essenciais ao metabolismo e reprodução microbianos, alterando enzimas, fosfolipídeos, DNA e RNA causando a inativação destes microrganismos. Esta reação ocorre rapidamente tornando o produto estéril em um curto espaço de tempo $[6,11]$.

$\mathrm{O}$ tratamento por plasma tem se mostrado efetivo no controle de esporos, fungos, bactérias e até mesmo vírus [6,11].

Há resultados muito promissores quanto ao uso de plasma frio no controle de microrganismos em morangos, maçãs, melões, mangas, peras, pimentas e nozes [6].

\section{Materiais e Métodos}

O plasma usado é formado por descarga em barreira dielétrica (DBD), com gás argônio ( $\mathrm{Ar}$ ) à uma vazão de $5 \mathrm{~L} / \mathrm{mim}$ como gás de trabalho. $\mathrm{O}$ dispositivo opera com plasma em regime difuso, a tensão aplicada entre os eletrodos é de $15 \mathrm{KV}$, à $1200 \mathrm{~Hz}$ de frequência [12].

As mangas da variedade coquinho foram coletadas no pomar de maneira aleatória e não foram submetidas a nenhum outro tipo de tratamento.
As mangas foram divididas em três grupos, grupo de tratamento direto, grupo de tratamento dentro do béquer e grupo controle.

O objetivo do tratamento no béquer foi concentrar o ozônio e os radicais produzidos em torno da amostra.

Nos grupos 1 e 2 o tempo de exposição ao plasma foi de 3 minutos, girando o produto a fim de ter um tratamento uniforme por toda a superfície (no grupo 2 a amostra foi girada dentro do béquer).

Nas figuras 1 e 2 é possível ver o plasma em contato com a superfície das mangas.

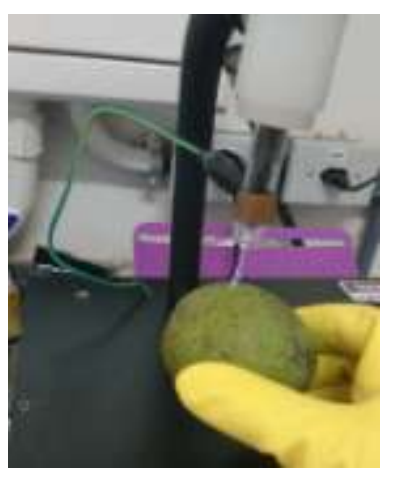

Figura 1: Grupo 1, tratamento direto

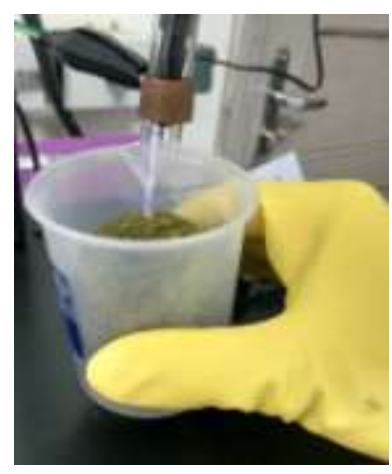

Figura 3: Grupo 2, grupo de tratamento no béquer
Após o tratamento, os grupos 1 e 2 foram acondicionados junto ao grupo controle em um local seco, fresco e ao abrigo da luz solar. Foram observados periodicamente os grupos pelo prazo de uma semana.

\section{Resultados e Discussões}

$\mathrm{Na}$ figura 3, pode-se observar os grupos de mangas submetidos ao tratamento à plasma frio e a amostra de controle uma semana após o tratamento. Foram utilizadas quatro mangas para esta análise.

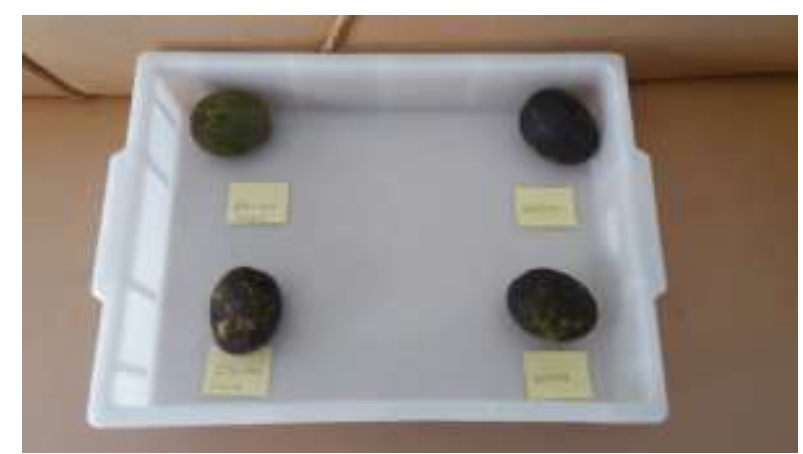

Figura 2: mangas da variedade coquinho após uma semana de tratamento com plasma frio

$\mathrm{Na}$ imagem é apresentado quatro mangas: a manga superior à esquerda é a submetida ao tratamento dentro do béquer (grupo 2), a manga inferior à esquerda foi a submetida a tratamento direto (grupo 1), as duas mangas na parte superior e inferior à direita são o grupo controle. Foi observado que há diferenças na quantidade de manchas escuras na superfície, a manga do grupo 2 apresentou uma menor quantidade 
de manchas em relação aos demais grupos. Este resultado pode ser influência da maior concentração de ozônio em torno da amostra. Estas manchas nos frutos são ocasionadas por microrganismos fitopatogênicos destacando-se o fungo Colletotrichum gloeosporioides e diminuem o tempo de prateleira uma vez que, essas manchas ao se coalescerem aumentam de tamanho e tornam o produto não comercializável [13]. As mangas tratadas com plasma frio apresentaram menor quantidade manchas escuras. Desta forma, o tratamento com plasma mostrou-se eficaz no retardamento do crescimento de manchas na superfície da amostra. Ou seja, o fungo causador de dano na superfície da manga foi inativado e, por consequência há um aumento o tempo de vida útil das mangas.

\section{Conclusão}

Foi possível concluir que o uso de plasma frio usando argônio como gás de trabalho mostrou resultados de inativação de microrganismos e aumento da vida útil de mangas da variedade coquinho com apenas três minutos de tratamento. Estes resultados são ainda preliminares, este tipo de tratamento ainda carece de mais estudos, aumentado a quantidade de amostras, variando o gás de trabalho e otimizando a energia do plasma. Deseja-se futuramente variar as amostras estendendo o tratamento a outros alimentos.

\section{Agradecimentos}

Os autores agradecem a CAPES pelo apoio financeiro.

\section{Referências}

[1] FAO; Rome Declaration on World Food Security. Food and Agriculture Organization of the United Nations (FAO). Disponível em: <http://www.fao.org/docrep/003/w3613e/w3613e00.HT $\mathrm{M}>$ acesso em 09 de ago. de 2017.

[2] MARTINS, F. C.; FARIAS, R. M. Produção de Alimentos $x$ Desperdício: Tipos, Causas e como Reduzir Perdas na Produção Agrícola - Revisão. Revista da FZVA, Uruguaiana, v. 9, n. 1, p. 20-32. 2002.

[3] DIONYSIO, R. B.; MEIRELLES, F. V. P.; Conservação de Alimentos. Disponível em $<$ http://web.ccead.puc-

rio.br/condigital/mvsl/Sala\%20de\%20Leitura/conteudos/ SL_conservacao_de_alimentos.pdf> Acesso 09 de ago. de 2017.

[4] ORNELLAS, C. B. D.; et al. Atitude do Consumidor Frente à Irradiação de Alimentos. Ciênc. Tecnol. Aliment, Campinas, 26(1): 211-213, jan./mar. 2006.
[5] SOUSA, T. L. T. L.; et al. Vantagens e Desvantagens da Irradiação na Conservação de Alimentos. Xiii Jornada de Ensino, Pesquisa e Extensão-JEPEX 2013 -UFRPE: Recife, 2013.

[6] OLIVEIRA DOS SANTOS JÚNIOR, L. C.; Efeitos da esterilização e de tratamentos não térmicos sobre as características físico-químicas e microbiológicas do purê de abóbora (cucurbita moschata). Tese (Doutorado em Engenharia de Alimentos), Programa de Pós-Graduação em Engenharia de Alimentos, Universidade Federal de Santa Catarina, Florianópolis, Santa Catarina, 2016.

[7] ALEXANDRE, F. A.; FARIA, J. F.; CARDOSO, C. F.; Avaliação da Eficiência da Radiação Ultra Violeta da Esterilização de Embalagens Plásticas. 1524 Ciênc. agrotec, Lavras, v. 32, n. 5, p. 1524-1530, set./out., 2008.

[8] SANTOS, A. C. P. Redução aluminotérmica do óxido de tântalo usando uma tocha de plasma como ignitor. Tese (Doutorado em Engenharia de materiais), Programa de Pós-Graduação em Ciências e Engenharia de Materiais, Centro de Ciências Exatas e da Terra, Universidade Federal do Rio Grande do Norte, Natal, Rio grande do Norte, 2007.

[9] FARIAS, E. E. Estudo do Plasma produzido por descarga elétrica no limiar da transição Townsend "glow". Dissertação (Mestrado em Plasmas em Ciências Físicas), Programa Pós-Graduação em Física, Universidade Federal Fluminense, Niterói, Rio de Janeiro, 2006.

[10] FELIPINI, C. L. Noções sobre plasma térmico e suas principais aplicações. Usjt integração. № 41. p. 147-151, 2005.

[11] BRASIL, Ministério da Saúde, Orientações Gerais para Central de Esterilizações. Secretaria de assistência à saúde. Rio de Janeiro-RJ. 2011.

[12] ALVES, D. P. Construção de um reator de plasma frio à pressão atmosférica. Trabalho de Conclusão de curso (Licenciatura em Física), Centro de Ciências Exatas, Naturais e da Saúde, Universidade Federal do Espírito Santo, Alegre, Espírito Santo, 2016.

[13] MAIA, F. G. M.; et al. Efeito da temperatura no crescimento micelial, produção e germinação de conídios de colletotrichum spp. isolados de mangueira com sintomas de antracnose. Bioscience Journal, Uberlândia, v. 27, n. 2, p. 205-210, Mar./Apr. 2011. 